ISSN $2006-6996$

\title{
EVALUATING THE EFFECT OF SPHERICAL CRYSTALLIZATION OF ACETYLSALICYLIC ACID CRYSTAL AND CRYSTAL AGGLOMERATION OF ManihotesculentaSTARCH ON DIRECT COMPRESSION TABLET PROPERTIES
}

\author{
Nnamani, N. D. $*^{1}$ Okafor, I. S. ${ }^{2}$ and Ume, $0, \mathbf{N}^{3}$ \\ ${ }^{1}$ Department of Pharmaceutics and Pharmaceutical Technology, College of Pharmacy, Igbinedion \\ University, Okada, Edo State, Nigeria \\ ${ }^{2}$ Department of Pharmaceutics and Pharmaceutical Technology, Faculty of Pharmaceutical Sciences, \\ University of Jos, Nigeria \\ ${ }^{3}$ Department of Pharmaceutical Chemistry, College of Pharmacy, Igbinedion University, Okada, Edo \\ State, Nigeria \\ nnamani.didacus@iuokada.edu.ng: 08033276431
}

\begin{abstract}
Spherical crystallization and crystal agglomeration have been used to optimize compact crystals and functional properties of powders. The aim of this work is to evaluate the effect of spherical crystallization of acetylsalicylic acid crystals and crystal agglomeration of Manihotesculenta starch on direct compression tablet. Typical spherical crystallization using three solvent system of water-ethanol-carbon tetrachloride was used to produce spherical acetylsalicylic acid. Salting-out agglomeration ofgelling in water and salting-out in ethanol was used to produce starch-xerogel from Manihotesculenta starch. The modified products were qualified using FT-IR analysis. The analysis results showed that modification did not alter chemical nature of the products. Acetylsalicylic acid tablets were formulated using spherical-crystallizedacetylsalicylic acid with 5 and $10 \%$ $w / w$ starch-xerogel respectively, and using acetylsalicylic acid with 5 and $10 \% \mathrm{w} / \mathrm{w}$ of starch, and microcrystalline cellulose respectively. The physicochemical properties of the tablets were evaluated. Astatistical $2^{3}$ factorial design of the tablet properties at $5 \%$ level of significance showed that the effects of the variables are significantly different.Theacetylsalicylic acid tablets formulated from direct compression of sphericalcrystallizedacetylsalicylic acid with $5 \% \mathrm{w} / \mathrm{w}_{\text {starch-xerogel produced quality tablets }}$ comparable tostandard tablets from direct compression of acetylsalicylic acid with10\% $w / w$ microcrystalline cellulose.Spherical crystallization and crystal agglomeration optimized the compact crystals of starch and acetylsalicylic acid, and improved direct compression properties of the crystals, and drug release from tablet.

Keywords: Spherical-crystallization, crystal-agglomeration, starch-xerogel, direct compression.
\end{abstract}

\section{INTRODUCTION}

Various agglomeration techniques such as traditional salting-out precipitation, cooling crystallization, crystallization from melting, and newer typical and non-typical spherical crystallization have been used to transform drug materials into compact spherical crystal agglomerates (Goczo et al., 2000; Nnamani et al., 2020). According to Goczo et al. (2000) spherical crystallization of acetylsalicylic acid crystal produced compact crystals with better flow, compressibility, size distribution and density suitable for direct compression. The acetylsalicylic acid is a non-steroidal antiinflammatory drug(Emdex, 2013). Acetylsalicylic acid crystal is colorless or white crystalline and odorless powder or granule with slightly acidic taste that is compounded to tablet mainly by direct compression (International Pharmacopoeia, 2006).

Direct compression is an efficient means of tablet production because of its ease, low cost and speed of production (Olowosuluet al., 2011). In direct compression of tablets, extragranular disintegrant is required to promote breakup of tablets to their pre-formulation fragments (granules and powders) in aqueous environment thereby increasing surface area and chances of release of drug active (Mehta, et al., 2012; Delalondeet al., 2015). 
BAJOPAS Volume 13 Number 2,December, 2020

Extra-granular disintegrants in direct compression break dosage form and make them available for dissolution, unlike intra-granular disintegrants of wet granulation which break granules back to their powder form (Mesnier et al., 2012; Mitraet al., 2018). Disintegrants such asstarch, microcrystalline, effervescence sodium bicarbonate with citric or tartaric acid, ion exchange resins (aberlite 88), and cross- linked polyvinylpylorridone are used in pharmaceutical formulations (Carter, 2002; Remya et al., 2010). Native starch is the earliest excipient used as disintegration agent at the range of $5-10 \%$. But below $5 \%$, starch has insufficient particle to create channel for wicking and swelling action for disintegration. Above $10 \%$ starch may form obstructive gel on wicking and swelling, may also hinder flow and compressive ability of formulation. Other drawbacks to starch application can been corrected by physical, chemical, enzymatic and other modification processes. Modified starches have improved noticeable intrinsic functional properties such as flow, compressibility, disintegration, binding and lubrication (Gohel, 2005; Mishra \& Rai, 2006; Chiu \& Solarek, 2009; Olowosulu et al., 2011). The disintegration properties of starch can be further modified to produce superdisintegrants such as sodium carboxymethyl starch (sodium starch glycolate), cross-linked sodium carboxymethyl cellulose (croscarmellose sodium), and accelerated dissolution (Ac-DiSol)suitable for direct compression (Carter, 2002; Remyaet al., 2010).

Manihotesculenta plant tuber starch has high crystalline amylopectin content and otherintrinsic properties and have been modified for different uses(Newman et al., 2007). Manihotesculenta starch has been used as disintegrating agent in tablet compression, with properties similar to those of Starch-1500 (Okafor et al., 2001). Modified Manihotutilissima tuber starch have been used to optimize metronidazole tablet formulation (Nnamani \& Okonkwo, 2017). Modified Manihotesculenta starch have been used in direct compression of acetylsalicylic acid crystals (Nnamani et al., 2020).

The objective of this work is to modify acetylsalicylic acid crystals using typical spherical crystallization method, and also modify Manihotesculenta plant tuber starch using crystal agglomeration method, and use these modified products in formulation for direct compression of tablet. The formulated test tablet will be compared with standard acetylsalicylic acid tablet formulated from acetylsalicylic acid crystal active ingredient and microcrystalline cellulose disintegrant, and unmodified formulation of acetylsalicylic acid crystals active ingredient and native Manihotesculenta starch disintegrant.

\section{MATERIALS}

The materials used in this study include Manihotesculenta (Crantz) starch from Paxherbal Clinic and Research Laboratories Herbarium, Ewu, Edo State, Nigeria (designated $P A X / H / 1933)$, microcrystalline cellulose (VijlakPharma Limited, India), and citric, talc andstearic acid (Takehara, Kagaku Kogy company Limited, Japan). The other reagents used were of analytical grade.

The equipment used includevibro screen machine (Gyro screen: Model GSV 180, ETA Engineering Services, Gurat, India),FTIR-8400S Fourier Transform Infrared Spectrophotometer (Shumadzu, Kyoto, Japan), Accuplate Hotplate stirrer (Model D0420, Labnet International, United Kingdom), Type F3 single punch machine (Model F3-1L1N0, Manesty Machines Limited, England), single drum friabilator (PTF 10E, Pharma Test Instruments, India Pvt. Limited, India), Monsanto tablet hardness tester (Model MHT-20 Thermonik, Campbell Electronic, India), disintegration tester (DT) (MK4, Manesty

Machine Limited, England),

\section{MATERIALS AND METHODS}

Extraction, Modification and Test for Starch and Starch Product

The Manihotesculenta (Crantz) plant and tubers were identified by Paxherbal Clinic and Research Laboratories Herbarium, Ewu, Edo State, with taxonomical identification herbarium number $\mathrm{PAX} / \mathrm{H} / 1933$. The method of Nnamani and Okonkwo (2017) was used to extract Manihotesculenta starch. The method of Nnamani et al. (2020) was used to obtain starch-xerogel from the Manihotesculenta starch. The Manihotesculenta starch and starchxerogel were tested for starch using iodinepotassium iodide solution.

\section{Preparation of test spherical crystallized} acetylsalicylic acid crystals

Using the method of Goczo et al (2000) for crystallization by solvent change, acetylsalicylic acid crystals was dissolved in twice its weight of $40 \% \mathrm{v} / \mathrm{v}$ ethanol and heated to $50^{\circ} \mathrm{C}$. Equal weight of $4 \% \mathrm{w} / \mathrm{v}$ carbon tetrachloride - water mixture was added to the solution, stirred at 200 rpm for 50 min with cooling at $0.6{ }^{\circ} \mathrm{C} / \mathrm{min}$ to 20 ${ }^{\circ} \mathrm{C}$. The spherically crystallized acetylsalicylic acid crystals was sieved out using a vibro screen machine (Gyro screen: Model GSV 180, ETA Engineering Services, Gurat, India)and air-dried. 
BAJOPAS Volume 13 Number 2,December, 2020

FT-IR Analysis and Chemical evaluation of spherically crystallized acetylsalicylic acid crystal

The fusion method reported by Leuner and Dressman (2000) was adopted in preparing solid dispersion spherical crystallized acetylsalicylic acid crystals in starch-xerogel. Using the method explained by Nnamani and Kashimawo (2020), $200 \mathrm{mg}$ of Manihotesculentacryatal starchxerogel was weighed and placed in a cubicle on a hot water bath and heated with constant stirring to $60{ }^{\circ} \mathrm{C}$ for 30 minutes. A $200 \mathrm{mg}$ of corresponding formulation spherical crystallized acetylsalicylic acid crystals was incorporated into heated the starch-xerogel in the cubicle and mixed by stirring for 2 minutes. The spherical acetylsalicylic acid - starch-xerogel solid dispersion (1:1) produced was allowed to cool. A $2 \mathrm{mg}$ of the 1:1 solid dispersions was weighed and made to $200 \mathrm{mg}$ with potassium bromide $(\mathrm{KBr})$ to produce $1 \%$ solid dispersion in $\mathrm{KBr}$ mixture. The mixture was pulverised and dried in a vacuum oven at $110{ }^{\circ} \mathrm{C}$ for 2 hours. The dried mixture was allowed to cool and fed into $13 \mathrm{~mm}$ diameter pellet-forming die and compressed by a press gauge at 8 tons for 3 minute to produce $80 \mathrm{mg}$ pellet.Using the same method of producing $1 \%$ solid dispersion in $\mathrm{KBr}$ mixture, but with $1 \%$ pure API in place of $1: 1$ solid dispersion, $1 \%$ pure API in $\mathrm{KBr}$ mixtures was formulated and compressed to $80 \mathrm{mg}$ pellet. Plain $\mathrm{KBr}$ pellet were also produced for use to standardize and set the background of the spectrophotometer reading using FTIR-8400S Fourier Transform Infrared Spectrophotometer
(Shumadzu, Kyoto, Japan). The FT - IR absorbance, at different wavelength, of the pellets of the $1 \% 1: 1$ solid dispersion in $\mathrm{KBr}$ and the $1 \%$ pure API in $\mathrm{KBr}$ mixtures were recorded and used to evaluate compatibility.

\section{Formulation ofacetylsalicylicacidgranules}

Using the formula in table 1 ,acetylsalicylicacidcrystal active ingredientwas blended with microcrystalline cellulosefor batches B and C, spherically crystallized acetylsalicylic acid crystals was blended with starch-xerogelforbatchesD and Ewas blended with microcrystalline cellulose, and acetylsalicylic acid was blended with Manihotesculenta native starchfor batches $F$ and $G$ respectively in an Accuplate Hotplate stirrer (Model D0420, Labnet International, United Kingdom) for 2 minutes. The respective batches were blended with lactose for $2 \mathrm{~min}$, and then citric acid, stearic acid and talc was added to the stirrer and mixed for 3 minutes to produce acetylsalicylic acid granules. The batches were then stored for analysis and compression.

Compression of acetylsalicylic acid granules to tablet

Using a Type F3 single punch machine (Model F3-1L1N0, Manesty Machines Limited, England), $325 \mathrm{mg}$ quantity of granules from each batch was manually fed into the die cavity of the single punch tabletting machine, fitted with a set of 10 $\mathrm{mm}$ flat-faced punches and die sets set to produce $325 \mathrm{mg}$ tablets compressed at $35 \mathrm{KN}$ pressure and speed of 1,800 TPH (tablet per hour). The tablets produced were collected, packed in a dry air tight container, and labelled.

Table 1: Formula for Preparing Tablets with Different Test Disintegrant

\begin{tabular}{lllllllllll}
\hline Batch & ASA & SCASA & NMS & $\begin{array}{l}\text { Starch- } \\
\text { xerogel }\end{array}$ & $\begin{array}{l}\text { MCC } \\
(\mathrm{mg})\end{array}$ & $\begin{array}{l}\text { Lactose } \\
(\mathrm{mg})\end{array}$ & $\begin{array}{l}\mathrm{C} / \mathrm{S} \\
(\mathrm{mg})\end{array}$ & $\begin{array}{l}\text { Talc } \\
(\mathrm{mg})\end{array}$ & $\begin{array}{l}\text { Tablet } \\
(\mathrm{mg})\end{array}$ & $\begin{array}{l}\mathrm{CP} \\
(\mathrm{N} / \mathrm{M})\end{array}$ \\
\hline $\mathrm{A}$ & 300.0 & 0.0 & 0 & 0 & 0 & 37.0 & 1.5 & 1.5 & 340 & 35 \\
$\mathrm{~B}$ & 300.0 & 0.0 & 0.0 & 0.0 & 17.0 & 20.0 & 1.5 & 1.5 & 340 & 35 \\
$\mathrm{C}$ & 300.0 & 0.0 & 0.0 & 0.0 & 34.0 & 3.0 & 1.5 & 1.5 & 340 & 35 \\
$\mathrm{D}$ & 0.0 & 300.0 & 0.0 & 17.0 & 0.0 & 20.0 & 1.5 & 1.5 & 340 & 35 \\
$\mathrm{E}$ & 0.0 & 300.0 & 0.0 & 34.0 & 0.0 & 3.0 & 1.5 & 1.5 & 340 & 35 \\
F & 300.0 & 0.0 & 17.0 & 0.0 & 0.0 & 20.0 & 1.5 & 1.5 & 340 & 35 \\
G & 300.0 & 0.0 & 34.0 & 0.0 & 0.0 & 3.0 & 1.5 & 1.5 & 340 & 35 \\
\hline
\end{tabular}

$\begin{array}{ll}\text { Key: } & \\ \text { ASA } & =\text { Acetylsalicylic acid } \\ \text { SCASA } & =\text { Spherically crystallized acetylsalicylic acid } \\ \text { NMS } & =\text { Native Mannihotesculenta starch } \\ \text { MCC } & =\text { Microcrystalline cellulose } \\ \text { C/S } & =1: 1 \text { ratio of citric and stearic acid } \\ \text { Tac } & =\text { Talcum powder } \\ \text { CP } & =\text { Compression pressure }\end{array}$


BAJOPAS Volume 13 Number 2,December, 2020

\section{Physicochemical evaluation of acetylsalicylic acid tablets}

Using the International Pharmacopoeia (2006) specification, the physicochemical properties of the tablets were evaluated. Weight variation test was done using 20 tablets from each batch of tablets were randomly selected and weighed individually using Ohaus digital weighing scale (Model SP 202). Friability test was done using a single drum friabilator (PTF 10E, Pharma Test Instruments, India Pvt. Limited, India), and the method described by Alderborn (2002) as a guide, with 10 tablets each from the formulated batches of tablets were weighed and placed inside the single drum friabilator. Hardness test was done using the Monsanto tablet hardness tester (Model MHT-20 Thermonik, Campbell Electronic, India) and the method described by Alderborn (2002) as a guide, with 10 tablets from each formulation were randomly selected. Disintegration test was performed on six tablets from each batch, using a disintegration tester (DT) (MK4, Manesty Machine Limited., England) operated at 30 cycle/ $\mathrm{mm}$ in a disintegration medium of $1000 \mathrm{ml}$ of $0.1 \mathrm{~N} \mathrm{HCl}$ at a temperature of $37{ }^{\circ} \mathrm{C}$. The tests were repeated in triplicate, and the results were recorded and evaluated.

\section{Statistical analysis of the physicochemical} properties of the tablets

Using a $4 \times 2$ contingency table computation for one-way ANOVA of Kothari and Gaurav (2014), the effect of independent formulations and xerogel and microcrystalline variables, which significantly influenced disintegration, friability and hardness at different concentration level were analyzed for the batches.

\section{RESULTS}

Extraction, Modification and Test for Starch

The starch gave a blue black coloration with the test iodine, while theblue black color of the starch-xerogel appeared lighter. The starch appeared white and dense to the eye, while the starch-xerogel appeared more crystalline, whiter, slightly translucent and grittier to touch and odorless.

Chemical Evaluation of Acetylsalicylic acid and Modified Blends in Test Granules

Using the interpretation of Jacox and Thompson (2013), the FT - IR absorption vibration frequencies (Tables 2) show no interference, no new peak and no new absorption band on acetylsalicylic acid was formed by the spherically crystallized acetylsalicylic acid - starch-xerogel dispersion.

Physicochemical Properties of Formulated Acetylsalicylic acid Tablets

The tablets showed good physicochemical properties of weight uniformity (Table 3). All the test tablets had good tablet hardness. The per cent friability ( $\geq 1 \%$ ) of the tablets were good for all the tablets with disintegrant. The disintegration time of pure acetylsalicylic acid tablet (without standard or test disintegrant) refused to disintegrate after $3 \mathrm{hrs}$. Tablet formulations with $5 \% \mathrm{w} /{ }_{w}$ MCC in acetylsalicylic acid, and those with 5 and $10 \% \mathrm{w} /{ }_{\mathrm{w}}$ native starchin acetylsalicylic acid crystals did not disintegrate in $4 \mathrm{~min}$. Tablet formulation with standard $10 \% \mathrm{w} / \mathrm{w}$ MCC in acetylsalicylic acid, and test $5 \% w / w$ and $10 \% \quad w / w$ starchxerogelin spherically crystallized acetylsalicylic acid crystal formulations disintegrated before 4 min.

\section{Statistical Analysis}

The F-ratio resultof the hardness, friability and disintegration time statistics were greater than the critical value of F-table and follows Snedico's F-distribution with $(k-1)$, (n-k) degree of freedom as a right tailed test (Table 4). The comparison of the critical difference to the difference of sample mean between pair of formulation batches differs significant (Table 5).

Table 2: FT - IR Stretching Vibrations Absorption Frequency of Acetylsalicylic acid (cm $\left.{ }^{-1}\right)$

\begin{tabular}{|c|c|c|c|}
\hline \multicolumn{2}{|c|}{ Absorption band } & \multicolumn{2}{|l|}{ Inference } \\
\hline ASA & $\mathrm{SCASA}+\mathrm{X}$ & Vibration mode & Functional group \\
\hline 3393 & 3450 & $\mathrm{O}-\mathrm{H}$ stretch (H-bonded) & carboxyl group \\
\hline 3100 & 3100 & $\mathrm{C}-\mathrm{H}$ stretch (aryl) & benzene ring \\
\hline 2998 & 3002 & C-H stretch (saturated) & aliphatic acyl group \\
\hline 2868 & 2869 & $\mathrm{C}-\mathrm{H}$ stretch (unsaturated) & aliphatic acyl group \\
\hline 2676 & 2676 & $\mathrm{O}-\mathrm{H}$ stretch (carboxylic acid dimer) & carboxyl group \\
\hline 2567 & 2577 & O-H stretch (carboxylic acid dimer) & carboxyl group \\
\hline 1694 & 1700 & $-\mathrm{C}=\mathrm{O}$ stretch & carboxylic acid \\
\hline 1600 & 1600 & $\mathrm{C}=\mathrm{C}$ stretch & benzene ring \\
\hline \multicolumn{4}{|l|}{ Key } \\
\hline $\begin{array}{l}\text { ASA } \\
\text { SCASA } \\
=\end{array}$ & $\begin{array}{l}\text { FT - } \\
\text { disper }\end{array}$ & $\begin{array}{l}\text { sorption band of pure acetylsalicyli } \\
\text { absorption band of spherical ac } \\
\text { with Manihotesculentaxerogel }\end{array}$ & $\begin{array}{l}\text { ylic acid in ratio } 1: 1 \text { solid } \\
\text { yli }\end{array}$ \\
\hline
\end{tabular}


BAJOPAS Volume 13 Number 2,December, 2020

Table 3: Physicochemical Properties of Formulated Acetylsalicylic acid Tablets

\begin{tabular}{|c|c|c|c|c|c|}
\hline Batch number & Variant factor & $\begin{array}{l}\text { Weight (mg) } \\
\pm S D\end{array}$ & $\begin{array}{l}\text { Hardness (KgF) } \\
\pm \text { SD }\end{array}$ & $\begin{array}{l}\text { Friability (\%) } \\
\pm \text { SD }\end{array}$ & $\mathrm{DT}(\min ) \pm \mathrm{SD}$ \\
\hline A & A & $325 \pm .00$ & $6.67 \pm 0.16$ & $6.00 \pm 0.03$ & $180.00 \pm 3.30$ \\
\hline B & AM5 & $325 \pm .00$ & $4.50 \pm 0.13$ & $0.52 \pm 0.01$ & $6.70 \pm 0.25$ \\
\hline C & AM10 & $325 \pm .00$ & $3.50 \pm 0.11$ & $0.50 \pm 0.01$ & $1.80 \pm 0.04$ \\
\hline D & AX5 & $325 \pm .00$ & $3.50 \pm 0.17$ & $0.52 \pm 0.02$ & $1.72 \pm 1.02$ \\
\hline$E$ & AX10 & $325 \pm .00$ & $3.17 \pm 0.09$ & $0.59 \pm 0.00$ & $1.80 \pm 0.05$ \\
\hline $\mathrm{F}$ & AX5 & $325 \pm .00$ & $3.33 \pm 0.28$ & $1.06 \pm 0.02$ & $5.30 \pm 0.12$ \\
\hline G & AX10 & $325 \pm .00$ & $4.17 \pm 0.13$ & $1.01 \pm 0.01$ & $5.73 \pm 0.11$ \\
\hline
\end{tabular}

Key: DT $(\min )=$ disintegration time in minutes

SD: Standard deviation

Table 4: Analysis of Variance Table of One-way ANOVA Between and Within Samples B, C, $D$ and $E$

\begin{tabular}{llll}
\hline Source of variation & Hardness & Friability & Disintegration \\
\hline F-ratio (variance ratio) & 39.04 & 17.31 & 336.96 \\
F-limit ( critical value F (at 5\% from the F-table) & 6.59 & 6.59 & 6.59 \\
Critical difference (CD) & 0.407 & 0.039 & 0.66
\end{tabular}

At $5 \%$ level of significance if F-ratio $>$ F-limit, we reject the null hypothesis $\mathbf{H}_{\mathbf{o}}$ and calculate critical difference

Table 5: Difference of Sample Means of Formulations B, C, D and E, and Conclusion at 5\% Level

\begin{tabular}{llll}
\hline $\begin{array}{l}\text { Pair of Treatment } \\
\text { (Between Batches) }\end{array}$ & Hardness (CD 0.407) & Friability (CD 0.039) & Disintegration (CD 0.66) \\
\hline B and C & 0.85 & 0.02 & 4.7 \\
B and D & 0.8 & 0.01 & 4.8 \\
B and E & 1.17 & 0.085 & 4.7 \\
C and D & 0.05 & 0.03 & 0.055 \\
C and E & 0.32 & 0.105 & 0.05 \\
D and E & 0.37 & 0.075 & 0.105 \\
\hline
\end{tabular}

Key

$C D=$ critical difference. (The difference in sample mean of the pair of treatment from the test $C D$ indicates that the pair of treatment differs significantly)

\section{DISCUSSION}

Both the native starch and the modified starchxerogelgave positive result for starch. This showed that modification of starch did not alter the chemical entity of starch. The FT-IR bands forvibrational modes of carboxyl, benzene, aliphatic and carboxylic functional groups identifying acetylsalicylic acid were largely unaffectedby the FT-IR band spectra of the spherically crystallized acetylsalicylic acid starch-xerogel dispersion. Using the interpretation of Jacox and Thompson (2013), this FT-IR result is an indication that the crystal modification of acetylsalicylic acid was physical and no new chemical compound was formed from the modification and the blending with starch-xerogel. All the variable tablets formulated passed tablet hardness and per cent friability test.The computed statistical F-ratio results of tablet per cent friability, hardness and disintegration timeshowed that effect of all pair of test variables differ at $5 \%$ level of significance. Acetylsalicylic acid crystal directly compressed without neither microcrystalline cellulose, starch nor modified starch formed hard tablets that fail to disintegrate. This indicates that directly compressible acetylsalicylic acid crystals requires additional disintegrant excipient to be functional. Tablets directly compressed from formulations of 5 and $10 \%$ $w / w$ native Manihotesculenta starch respectively in acetylsalicylic acid, and from formulation of $5 \% \mathrm{w} / \mathrm{w}$ microcrystalline cellulose in acetylsalicylic acidfailedtablet disintegration time test. Tablets directly compressed from formulations of spherically crystallized acetylsalicylic acid crystalscontaining $5 \%$ and $10 \%$ starch-xerogelrespectively, and from 
BAJOPAS Volume 13 Number 2,December, 2020 standard formulation of $10 \%$ microcrystalline cellulose in acetylsalicylic acid crystalspassedtablet disintegration time test.Crystallization of acetylsalicylic acid and starch resulted in improved powder flow and compression ability, and solubility, which is consistent with reports by Sumant (2014), Goczoet al (2000) and other researchers on effect of crystalline modification.

\section{CONCLUSION}

The standard acetylsalicylic acid tablet properties fromdirectly compression of acetylsalicylic acid with10 \% $\quad w / w \quad$ microcrystalline cellulosedisintegrant can be replicated withspherical crystallized acetylsalicylic acid $\begin{array}{llll}\text { crystal and } & 5 & - & 10 \%\end{array}$ w/w Manihotesculentastarch-xerogel. The

\section{REFERENCES}

Alderborn, G. (2002): Tablets and Compaction. In: Aulton, ME, Pharmaceutics, The Science of Dosage Form Design. Churchill Livingstone, London, 27: 397440.

Carter, J.C. (2002): The role of disintegrants in solid oral dosage manufacturing. Pharmaceutical Canada, Carter Pharmaceutical Consulting Inc. 3:2.

Chiu, C. and Solarek, D. (2009): Modification of starches. In: Starch: Chemistry and Technology, $3^{\text {rd }}$ edition, Elsevier Inc. London, 17: 629-645.

Delalonde, M., Fitouri, R., Ruiz, E., Bataille, B. and Sharkawi, T. (2015): Impact of physicochemical environment on the super disintegrant functionality of crosslinked carboxymethyl sodium starch: Insight on formulation precaution. $A A P S$ PharmSciTech, 16(2): 407-412. DOI: 10.1208/s12249-014-0121-z

EMDEX (2013): In Obi CC, The Complete Drug Formulary for Nigerian's Health Professional. Lindoz Products Limited, Lagos, 50-358.

Goczo, H., Szabo-revesz, P., Farkas, B., Hasznos-Nezdei, M., Serwanis, S.F., Pintye-Hodi, K., Kasa, Jr. P., Eros, I., Antal, I. and Marton, S. (2000): Development of spherical crystals of acetylsalicylic acid for direct tabletmaking. Chem. Pharm. Bull 48(12): $1877-1881$.

Gohel, M. (2005): A review of co-processed directly compressible excipients. Journal of Pharmacy and Pharmaceutical Sciences, 8 (1): 76-93.

International Pharmacopoeia. (2006): WHO, Geneva, (4 ${ }^{\text {th }}$ edn), 2: 946-967. properties of tablet from this dual modification is also an improvement from using acetylsalicylic active ingredient and native Manihotesculentastarch. Dual modification products from spherical crystallization of acetylsalicylic acid crystal and crystal agglomeration of nativeManihotesculentastarchare good for direct compression of tablet.

\section{Authors contribution}

DrNnamani carried out the pharmaceutical dosage formulation, production and tests. Professor Okafor designed (originally as postgraduate project work) and supervised the work, and also interpreted the physicochemical studies results. Ms Ume carried out the chemical analysis and interpretation of the FT-IR results.

Jacox, M.E. and Thompson, W.E. (2013): Absorptions between 3000 and $5500 \mathrm{~cm}^{-}$ ${ }^{1}$ of cyclic $04+$ and 04 - trapped in solid neon. Journal of Physical Chemistry A, 117: 13443-13449. DOI: 10.1021/jp4069174

Kothari, C.R. and Gaurav, G. (2014): Research Methodology: Methods and Techniques. New Age International (P) Limited Publishers, New Delhi; 3: 269 - 289.

Leuner, C. and Dressman, J. (2000): Improving drug solubility for oral delivery using solid dispersions. European Journal of Pharmaceutics and Biopharmaceutics, 50(1): 47-60. DOI: https://doi.orq/10.1016/s09396411(00)00076-X

Mehta, S., De Beer, T., Remon, J. and Vervaet, C. (2012): Effect of disintegrants on properties of multiparticulate tablets comprising starch pellets and excipient granules. International Journal of Pharmaceutics, 422 (1): 310-317. DOI: https://doi.org/10.1016/j.ijpharm.2011.1 1.017

Mesnier, X., Althaus, T.O., Forny, L., Niederreiter, G., Palzer, S., Hounslow, M.J. and Salman, A.D. (2013): A novel method to quantify tablet disintegration. Powder Technology, 238: 27-34.

Mishra, S. and Rai, T. (2006): Morphology and functional properties of corn, potato and tapioca starches. Food Hydrocolloids, 20 (5): 557-566. DOI: 10.1016/j.foodhyd.2005.01.001

Mitra, B., Hilden, J. and Litster, J. (2018): Assessment of intragranular and extragranular fractures in the development of tablet tensile strength. 
BAJOPAS Volume 13 Number 2,December, 2020 Journal of Pharmaceutical Sciences, 107(10): 2581-2591.

Newman, A.W., Mueller, R.L., Vitez, I.M. and Kiesnowski, C.C. (2007): Starch and Starch Derivatives. In :Encyclopaedia of Pharmaceutical Technology, 3467- 3481.

Nnamani, N. D. and Kashimawo, A. J. (2020). Design and evaluation of drug release kinetics of theophylline from coprocessed Colocosiaesculenta gum. Nigerial Journal of Pharmaceutical and Applied Sciences Research, 9(1): 55-62.

Nnamani, N. D., Oyeniyi, Y. J. and Okafor, I.S. (2020): The use of xerogel from Manihotesculenta as multipurpose excipient in sulphathiazide tablet formulation. Journal of Pharmaceutical and Allied Sciences, 17(1): 3234-3249.

Nnamani, N.D. and Okonkwo, J.N. (2017): Optimization of metronidazole tablet formulation using Manihotutilissima starch and a combination of processing techniques. Future Journal of Pharmaceutical Sciences, 3 (1): 65-70.

Okafor, I.S., Ofoefule, S.I. and Udeala, O.K. (2001): A comparative study of modified starches in direct compression of a water soluble drug (Hydrochlorothiazide). BollettinhimicoFarmaceutico, 140 (1): 36-39.
Olowosulu, A.K, Oyi, A., Isah, A.B. and Ibrahim, A. (2011): Formulation and evaluation of novel co-processed excipients of maize starch and acacia gum (StarcAC) for direct compression tableting. International Journal of Pharmaceutical Research and Innovation, 2: 39-45. DOI:

https:www.researchgate.net/publication/ 267368334

Remya, K.S., Beena, P., Bijesh, P.V. and Sheeba, A. (2010): Formulation development, evaluation and comparative study of effects of super disintegrants in cefixime oral disintegrating tablets. Journal of Young Pharmacists, 2(3): 234-239. DOI: https://doi.org/10.4103/0975-143/0975143.66794

Sumant, S. (2014): Spherical Crystallization- an overview. International Journal of Drug Delivery Technology, 4(4): 72-80. 